\title{
- COVID-19: Plasma Therapy and Stem Cell Therapy
}

\section{Anoop Kallingal}

IJCRR

Section: Healthcare

ISI Impact Factor

(2019-20): 1.628

IC Value (2019): 90.81

SJIF (2020) $=7.893$

(c) (i) (3)

Copyright@IJCRR
Department of Biotechnology and Microbiology, School of Life Sciences, Dr. Janaki Ammal Campus, Kannur University, Kannur 670661,

Kerala, India.

Email: anoopknair22@gmail.com
Lockdown, RT-PCR, Pandemic, Hotspot, N95 mask, PPE, Quarantine, Break the chain... These are some of the words that seeped into our everyday conversations after the Coronavirus took the world by a storm. For treating the COVID infection, two therapies have been approved: Plasma therapy and Stem cell therapy. Let's focus on both of them....

\section{PLASMA THERAPY}

When the germs of a particular disease enter our body, the white blood cells in our blood produce certain antibodies to the immune system. These immune cells fight the disease. When we are sick, we have a lot of these particles in our blood. Plasma is the fluid that is obtained by removing blood cells (red blood cells, white blood cells) from the blood. Plasma isolated from infected individuals may contain more antibodies against the disease. Plasma treatment is the process of separating and purifying plasma from a sick patient's body and donating it to a sick patient. Our immune system produces antibodies when we are sick and vaccinated to fight the disease, but it takes a little longer (2-4 weeks). If the condition is severe before the antibodies are produced in our body, the plasma extracted from the infected person can be given ready-made to the patient. These immune cells effectively fight off the spread of serious diseases. Antibodies are usually given for many diseases. This process of boosting the immune system is called passive immunity. But this type of immunity lasts for years. Antibody therapy is used for diseases such as jaundice and chickenpox. These antibodies are present in the blood of a person who has had a normal COVID. Plasma therapy involves removing an antibody from a person diagnosed with the disease and is now in a critical condition. COVID takes the blood of the person who came earlier and separates the plasma in it. Antibodies are formed in this plasma. The results were that it would be effective when that plasma was injected into the new patient's body. Plasma can be donated to women who have not yet become pregnant and to men between the ages of 18 and 65. They should weigh more than $50 \mathrm{~kg}$ and should be asymptomatic for two weeks. Plasma is taken 28 days after recovery. Only the required plasma is extracted from the blood by apheresis technology using the Frasinius Comtech machine. Ensure that there is no HIV, HBV, or HCV disease. The donor must have at least one of the antibodies needed to fight the COVID. COVID Convulsive Plasma Therapy is a method of treating COVID patients using COVID liberated individuals' blood plasma. More than 90 percent of patients survived this treatment. Plasma treatment is provided with the approval of the State Board and the Institutional Medical Board in accordance with the guidelines of ICMR and State Protocol. The Department of Health had earlier said that all government medical colleges and major COVID treatment centers in the state are treating COVID confirmed patients. The use of plasma treatment during outbreaks is not new. This treatment was used during the Spanish flu outbreak of 1918. Plasma treatment has also been successful during the 2015 MERS, 2009 H1N1, and 2014 Ebola virus outbreaks.

\section{STEM CELL THERAPY}

The stem cell is the primitive form of cells in the human body. Such cells have the ability to transform into any type of cell. These cells are usually isolated from the embryonic stem cells (ESCs). These cells are isolated from the placenta. Stem cells can be isolated from muscle, fat, liver, and bone marrow. Stem cell treatment is very effective for leukemia. At the time of COVID's outbreak in China, stem cell treatment was found to be effective. Essays on Stem Cell Treatment have been published at Yuan Hospital in Beijing. Stem cells taken from the placenta can be injected into a few people who have a serious illness and can reduce the disease's severity. Cytokine Storms is the most serious form of the disease. In such a case, such treatment can stimulate the patient's immune system. Stem cell treatment has been approved in countries such as the United States and Israel. Applications for licensing of stem cell therapy for COVID 
patients in India have been submitted by institutions such as the National Center for Cell Sciences in Pune. Like other therapies, stem cell therapy is now in its infancy. The world is waiting for more study reports.

\section{REFERENCE}

1. Chen L, Xiong J, Bao L, Shi Y. Convalescent plasma as a potential therapy for COVID-19. Lancet Infect Dis. 2020;20(4):398400 . 